\title{
Ильина И.Е. Основные подходы к изучению невербальных средств коммуникации
}

\author{
Ilina I.E. \\ Main approaches to the studying of nonverbal \\ means of communication
}

Рассмотрены вопросы вербальной и невербальной коммуникации, элементы языка тела, функции невербальной коммуникации. Невербальная коммуникация представлена как совокупность телодвижений, жестов, мимики, поз и частично интонаций. Невербальные компоненты коммуникации описаны как неотъемлемая часть человеческого общения, так как правильная интерпретация любого речевого высказывания невозможна без учета невербальных средств, которые иногда не просто дополняют вербальные акты, а выполняют основную функцию реализации интенции коммуниканта

Ключевые слова: невербальная коммуникация, жест, средства коммуникации

\section{Ильина Ирина Евгеньевна}

Кандидат философских наук, доцент

Тамбовский государственный технический университет

г. Тамбов, ул. Мичуринская, 112 A
The paper deals with verbal and non-verbal communication, body language elements, functions of nonverbal communication. Nonverbal communication includes body movements, gestures, facial expressions, posture and partly intonation. Nonverbal communication components are an integral part of human communication as a proper interpretation of any verbal expression is impossible without non-verbal means, which complement verbal acts, and express the basic intentions of communicats

Key words: nonverbal communication, gesture, communication means

Ilina Irina Evgenievna

Candidate of Philosophical Sciences, Associate

Professor

Tambov state technical university

Tambov, Michurinskaya st., 112 A

Постоянное взаимодействие между людьми в обществе происходит посредством общения. Язык всегда неотделим от человека, а последнее невозможно представить все его субъективных суждений и субъективных восприятий [5]. Структура общения характеризуется путем выделения в ней трех взаимосвязанных сторон: коммуникативной, интерактивной и перцептивной. Коммуникативная сторона общения или коммуникация в узком смысле слова состоит в обмене информацией между общающимися индивидами. Интерактивная сторона общения заключается в организации взаимодействия между общающимися индивидами, то есть не только в обмене знаниями и умениями, но и действиями. Перцептивная сторона общения рассматривается как процесс восприятия друг друга партнерами по общению и установления на этой основе взаимопонимания. 
Речевая коммуникация является цепочкой составляющих, в которой порождение, передача и прием вербального сообщения является лишь звеном общего процесса в целом. Наряду с акустическим каналом при передаче сообщения играет большую роль также и визуальный канал. Использование только языковых средств нельзя назвать сугубо обязательным. Часть информации во время общения человек получает с помощью невербальных средств, которые согласуются с вербальными средствами в силу единой биологической организации человека.

В самом общем виде корпус средств невербальной коммуникации можно определить как все неязыковые явления и способы поведения в интерактивном контексте. Невербальные средства охватывают все явления, действия и формы выражения, которые не являются частью языка (в смысле актуально использованных слов и языковых выражений), то есть все звуковые и речевые явления, паузы, неречевые звуковые выражения, все физические, мимические, жестовые формы выражения. Понятие невербальной коммуникации охватывает незвуковые невербальные и звуковые невербальные явления.

Аспекты невербальной коммуникации изучаются в рамках следующих научных направлений:

1) кинесику (наука о жестах, жестовых движениях, мимике, походке, по3ax).

2) проксемику (наука о пространстве коммуникации), включающую в себя расстояние между коммуникантами при различных видах общения.

3) гаптику (наука о языке касаний и тактильной коммуникации);

4) паралингвистику (наука о дополнительных к речи звуковых кодах, которые включены в процесс речевой коммуникации и которые могут передавать в этом процессе определенную информацию);

5) экстралингвистику (наука о неречевых вкраплениях в речь);

6) окулесику (наука о языке глаз и визуальном поведении людей во время общения), которая нередко выполняет контактно-регулирующую функцию;

7) ольфакцию (наука о языке запахов и их роли в коммуникации);

8) гастику (наука о знаковых и коммуникативных функциях пищи и напитков, приема пищи и угощений);

9) хронемику (наука о времени коммуникации, о его структурных, семиотических и культурных функциях);

10) аскультацию (наука о слуховом восприятии звуков и их семиотических функциях, а также об аудиальном поведении людей в процессе коммуникативного взаимодействия);

11) силенциальные и акциональные компоненты общения. Силенциальные акты (молчание) подробно исследовались рядом лингвистов. Акциональные компоненты представляют собой действия коммуникантов, сопровождающие речь. Например, в ответ на просьбу адресанта что-то сделать адресат может выполнить требуемое действие (например, выключить свет). Невербальные действия могут чередоваться с вербальными в процессе общения. Тем не менее, природа таких невербальных действий сугубо практическая. 
Слово «жест» восходит к латинскому слову «gerere», означающему «носить, нести ответственность, контролировать, выполнять, исполнять». В этимологическом словаре отмечается, что непосредственным предком слова «жест» является «gestura», слово из средневековой латыни, значение которого может быть описано как «способ ношения чего-либо или способ действия». А. Кендон обнаружил, что в британских трактатах, относящихся к риторике, это слово применялось только для обозначения правильного телесного поведения оратора во время произнесения речей, т.е. того, как оратор должен использовать возможности своего тела, чтобы воздействовать на слушателей. Понятие «gestus» было введено в 1936 г. Б. Брехтом для обозначения социального жеста, то есть жеста на сцене [4].

В 1952 г. Р. Бердвистел создал каталог отдельных простейший человеческих движений и статических поз. Элементарные акты человеческого поведения были названы им кинами («мельчайшие, далее делимые, наименее заметные движения»; «кины имеют чрезвычайно малую длительность, приблизительно 1/50 сек.») и кинемами («более крупные единицы, с помощью которых происходит реальное общение людей»; «кинемы образуют структуру и объединяются в более крупные единицы - кинеморфы и кинесинтагмы»).

В некоторых случаях трудно определить является невербальная единица жестом или физиологическим движением. Основной критерий отделения жестов от физиологических движений - это знаковый характер жеста. Жест, как и всякий знак, имеет означающее и означаемое, причем связь между ними носит в большинстве случаев конвенциональный характер. Поэтому движениями, а не жестами является, например, вращение головой из стороны в сторону, когда чешется. Жесты служат для выражения смысла, а, например, чихание не имеет семантической функции. Еще одно отличие - способность жестов менять значение в географическом и культурном пространстве и во времени. Например, сегодня лишь отдельные фразеологические выражения напоминают о жестах прошлого, ср.: бросить перчатку, разрешите откланяться, пасть на колени, челом бить, припасть к ногам и др. Физиологические движения в силу неконвенциональной связи между их формой и значением такой способностью не обладают. Интерпретация движения как жеста или как физиологической реакцией часто входит в функцию адресата актуальной ситуации невербального общения. Эта интерпретация может оказаться неправильной, и в таких случаях возможна коммуникативная неудача. Так, например, в разговоре один из собеседников зевнул. Другой может истолковать этот зевок двояким образом: либо как физиологическую реакцию, вызванную хроническим недосыпанием партнера, либо как знак, свидетельствующий о том, что зевнувшему разговор неинтересен или скучен. Не вполне четкая граница между жестами и физиологическими движениями и их общая биологическая основа частично объясняют, почему многие движения в коммуникативном акте могут сознательно использоваться как жесты. Так, желая обратить внимание адресата на то, что у него болит голова, адресант может приложить руку к голове, и в этом случае данное движение становится жестом. 
Необходимость изучения невербальных средств коммуникации отмечали русские языковеды.

Многие ученые занимались проблемой обучения невербальным средствам общения, подчеркивая огромную зависимость этой проблемы для адекватного восприятия высказываний, содержащих невербальные средства общения в практическом общении с носителями языка.

Краткий обзор работ, посвященных изучению невербальных средств общения, свидетельствует о большом интересе ученых-лингвистов к этой проблеме. Это объясняется той ролью, которую играют невербальные средства коммуникации в языковой системе в целом, и в коммуникативном акте в частности. Вместе с тем, необходимость данного исследования обусловлена появлением новых подходов к решению проблем языковой манифестации невербальных средств коммуникации в рамках диалогического дискурса, которые позволяют обнаружить новые принципы отображения жестов в языке и речи. Одним из таких является фреймовый подход, так как средства вербализации жестов представляют собой лексические единицы, принадлежащие к одной «теме» и, следовательно, имеют близкие мыслительные представления, поэтому они репрезентируют некоторую совокупность знаний о способах вербализации жестов, и знания эти существуют не как хаотичные нагромождения информации, а в виде логически организованной структуры. Такой структурой является жестовый фрейм, описание которого дает возможность выявить механизм языковой репрезентации невербальных средств коммуникации в диалогическом дискурсе.

Функциональное взаимодействие невербальных и вербальных средств, в частности то, что невербальные средства модифицируют и эксплицируют высказывание и обеспечивают успешное протекание непосредственной коммуникации, отмечалось многими учеными.

Однако исследователи по-разному оценивают функциональный статус невербальных средств в речевом общении.

Слово может обнаружить свою конечную суть только в контексте физической реальности - жеста, мимики, телодвижения - всякого околословесного действия [1]. Участие жестов в коммуникативном акте не всегда можно квалифицировать как второстепенное и вспомогательное, поскольку в реальной обстановке устного речевого общения реакция на определенное высказывание может быть невербальной, например, презрительный взгляд, ироническая улыбка, радостный смех, восторженный возглас. В таких случаях неречевые средства являются индикаторами успешности речевого взаимодействия. Они выступают неречевыми эквивалентами каких-то речевых действий и, возможно, более эмоциональными и экономичными [7].

Коммуникативная ситуация как часть объективной реальности представляет собой единство и соотношение речевых и неречевых элементов. Материальная конкретность коммуникативной ситуации допускает и предполагает сочетание вербальных и невербальных средств. Несмотря на то, что почти любой невербальный компонент может быть манифестирован в языковой форме, рассмотрение последовательностей речевых ходов и речевых интерак- 
ций, как и речевых событий, в целом, было бы неполно и неадекватно без учета неречевых ходов и неречевых интеракций.

Невербальные компоненты коммуникации являются неотъемлемой частью человеческого общения, так как правильная интерпретация любого речевого высказывания невозможна без учета невербальных средств, которые иногда не просто дополняют вербальные акты, а выполняют основную функцию реализации интенции коммуниканта [2]. Система человеческого общения - это многогранный целостный процесс, включающий вербальные и невербальные каналы, которые в разных ситуациях общения взаимодействуют различным образом, но всегда тесно связаны друг с другом [8].

Вербальные и невербальные компоненты в конкретной ситуации общения выступают в единстве, составляя основу коммуникативного акта. Речевое и неречевое поведение, вербальные (собственно речь, ее особенности) и невербальные формы речевого поведения (жест, мимика, интонация, поза, телодвижения и т.д.), выражающие эмоциональное и психологическое состояние, мотивированное условиями и обстоятельствами единого деятельностного акта, имеющего определенные мотивы и цели.

Невербальное поведение - это способ прочитать то, как чувствует себя клиент в данный момент. Невербальные сообщения часто отличаются от вербальных, а по совпадению и расхождениям между ними можно догадаться о том, что происходит в данный момент общения.

Выделяются следующие способы взаимодействия вербального и невербального поведения:

- повторение: невербальная коммуникация дублирует то, что было передано вербально;

- контрадикция: невербальное поведение противоречит вербальному;

- субституция: невербальное поведение заменяет вербальное средство передачи сообщения;

- дополнение: невербальное поведение развивает вербальное сообщение;

- акцентирование: невербальное поведение акцентирует общие части вербального сообщения;

- регулирование: невербальное поведение используется для того, чтобы регулировать коммуникативный поток между взаимодействующими индивидами [6].

Невербальные средства сокращают вербальный текст, заменяя слово и включая в диалог те или иные дополнительные смыслы. Выступая в роли самостоятельной реплики или включаясь в высказывание, состоящее из вербальных и невербальных элементов, жест обнаруживает богатейшие ресурсы как чисто информативные, так и экспрессивные [3].

Чаще всего жесты рук, сопровождающие реплику, употребляются для достижения однозначности, подтверждая смысл произносимого.

Иногда жесты рук выполняют функцию реплики, то есть используются автономно. Мимика и жест иногда играют роль реплики в диалоге, заменяя словесное выражение. Часто мимическая и жестовая реплики дают ответ 
раньше, чем речевая; один из собеседников только хочет возразить, собирается говорить, а другой, учитывая его мимику и позыв к реплике, довольствуется этими репликами.

Межу вербальным и невербальным способом общения обнаруживаются некоторые сходства. Среди общих черт выделяют следующие:

1. Единицы вербальной и невербальной коммуникации служат для передачи значений и употребляются в определенном контексте.

2. Значение единиц вербальной и невербальной коммуникации изменяются в пространстве, во времени, а также под действием изменяющихся социоэкономических и культурных условий.

3. Единицы вербальной и невербальной коммуникации индивидуальны, так как есть возможность выбора кинем, и национальны по своей сути.

\begin{tabular}{|c|c|}
\hline Вербальная коммуникация & Невербальная коммуникация \\
\hline $\begin{array}{l}\text { 1. Абстрактность: } \\
\text { - передача сообщения может состоять- } \\
\text { ся и в отсутствии коммуникатора; } \\
\text { - возможно обсуждение явлений, не } \\
\text { относящихся непосредственно к дан- } \\
\text { ной ситуации; } \\
\text { - возможность обсуждение абстракт- } \\
\text { ных понятий, таких как род, время, } \\
\text { вид, число, сущность, различие, цвет, } \\
\text { доброта и т.п. }\end{array}$ & $\begin{array}{l}\text { 1. Конкретность: } \\
\text { - передача сообщения может состояться } \\
\text { только в присутствии коммуникатора; } \\
\text { - связь с непосредственной ситуацией } \\
\text { общения; } \\
\text { - обсуждение абстрактных понятий за- } \\
\text { труднено. }\end{array}$ \\
\hline $\begin{array}{l}\text { 2. Отсутствие сходства между обозна- } \\
\text { чением (словом) и обозначаемым (яв- } \\
\text { лением). }\end{array}$ & $\begin{array}{l}\text { 2. Подобие между обозначением и обо- } \\
\text { значаемым. }\end{array}$ \\
\hline $\begin{array}{l}\text { 3. Дискретность. } \\
\text { Составные элементы вербального со- } \\
\text { общения - буквы, слова, предложения, } \\
\text { фразы - четко отделены друг от друга, } \\
\text { их соотношение подчинено опреде- } \\
\text { ленным правилам. }\end{array}$ & $\begin{array}{l}\text { 3. Континуальность. } \\
\text { Невербальные сообщения трудно разло- } \\
\text { жимы на отдельные единицы. }\end{array}$ \\
\hline $\begin{array}{l}\text { 4. Определенность, инвариантность. } \\
\text { Вербальное сообщение легко кодиру- } \\
\text { ется и декодируется. Между носителя- } \\
\text { ми языка существует определенное } \\
\text { согласие относительно формы, значе- } \\
\text { ния и употребления языковых единиц. }\end{array}$ & $\begin{array}{l}\text { 4. Вероятностность, вариабельность. } \\
\text { Невербальное сообение трудно подда- } \\
\text { ется декодированию. Невербальный язык } \\
\text { гораздо более неустойчивый и вариатив- } \\
\text { ный, что проявляется как в самих едини- } \\
\text { цах, так и в правилах их комбинирования. }\end{array}$ \\
\hline $\begin{array}{l}\text { 5. Линейная временная последова- } \\
\text { тельность. }\end{array}$ & $\begin{array}{l}\text { 5. Пространственно-временная целост- } \\
\text { ность. }\end{array}$ \\
\hline $\begin{array}{l}\text { 6. Осознанность, произвольность. } \\
\text { Вербальные высказывания в значи- } \\
\text { тельной степени осознанны, их легче } \\
\text { подвергнуть анализу, оценить, понять, } \\
\text { проконтролировать. }\end{array}$ & $\begin{array}{l}\text { 6. Неосознанность, непроизвольность. } \\
\text { Невербальное поведение спонтанно. Не- } \\
\text { высокая степень осознанности невер- } \\
\text { бального поведения не означает, что оно } \\
\text { совсем не поддается сознательному кон- } \\
\text { тролю. Степень, в которой невербальная } \\
\text { коммуникация поддается сознательному } \\
\text { контролю, зависит от системы, с помо- } \\
\text { щью которой она осуществляется. }\end{array}$ \\
\hline
\end{tabular}




\begin{tabular}{|c|c|}
\hline Вербальная коммуникация & Невербальная коммуникация \\
\hline & $\begin{array}{l}\text { Например, П. Экман и У. Фризен разрабо- } \\
\text { тали концепцию «невербальной утечки } \\
\text { информации». Они проранжировали раз- } \\
\text { ные части тела по их способности к пере- } \\
\text { даче информации. Эту способность они } \\
\text { определили на основе трех параметров: } \\
\text { - среднее время передачи информации; } \\
\text { - количество невербальных паттернов, } \\
\text { которые могут быть представлены дан- } \\
\text { ной частью тела; } \\
\text { - степень доступности для наблюдений } \\
\text { за данной частью тела. } \\
\text { Самым мощным передатчиком информа- } \\
\text { ции по их классификации является лицо } \\
\text { человека. Движения ног и ступней ног за- } \\
\text { нимают на шкале «утечки информации» } \\
\text { последнее место, так как они не отлича- } \\
\text { ются особой подвижностью, имеют огра- } \\
\text { ниченное число движений и часто скры- } \\
\text { ты от наблюдателя. Поэтому люди чаще } \\
\text { всего контролируют выражение лица и } \\
\text { не обращают внимание на движения сво- } \\
\text { их ног, благодаря которым и происходит } \\
\text { «утечка информации». }\end{array}$ \\
\hline $\begin{array}{l}\text { 7. Организованный процесс обучения } \\
\text { языку. } \\
\text { Говорить детей учат специально, се- } \\
\text { мья и общество уделяют этому доста- } \\
\text { точно много времени и сил. }\end{array}$ & $\begin{array}{l}\text { 7. Спонтанное изучение. } \\
\text { Невербальный язык люди, как правило, } \\
\text { успешно усваивают сами, путем наблю- } \\
\text { дения, подражания. }\end{array}$ \\
\hline 8. Относительно быстрое усвоение. & $\begin{array}{l}\text { 8. Относительно медленное усвоение. } \\
\text { Усвоение людьми нового языка тела про- } \\
\text { исходит значительно медленнее, чем } \\
\text { овладение новым вербальным языком. } \\
\text { Например, группа немецких ученых уста- } \\
\text { новила, что иммигранты из Турции быст- } \\
\text { рее и успешнее овладевают новым для } \\
\text { них немецким языком, чем столь же но- } \\
\text { вым языком немецких жестов. }\end{array}$ \\
\hline
\end{tabular}

Таким образом, невербальные средства коммуникации, их языковая манифестация и вербальная речь тесно связаны между собой в процессе коммуникации. Невербальные акты имеют обширный выразительный потенциал в контексте, их употребление не всегда является спонтанным. Невербальные средства могут выступать хранителями «свернутой информации», развертка которой осуществляется в конкретной ситуации общения.

В целом невербальной коммуникации присуще те же функции, что и коммуникации в целом. Среди них:

1. Передача и получение информации.

Невербальная коммуникация является:

- эквивалентом вербального сообщения; 
- показателем модальности сообщения. Люди делают большую паузу, готовясь сообщить плохую новость по сравнению с хорошей;

- способом установления обратной связи. Наблюдение за невербальным поведением собеседника позволяет человеку выбрать или вовремя сменить тему для обсуждения, определить степень понятности переданной информации. Например, одной из функций контакта глаз является проверка того, воспринято и понято ли переданное сообщение или какой-то его фрагмент, указание адресату, что говорящий закончил передачу тому некоей порции смысла;

- средством улучшения понимания и запоминания вербальной информации. В частности, люди лучше опознают фигуры, звуки, если их вербальное описание сопровождается невербальным. Особенное значение невербальные показатели приобретают в условиях когнитивной нагрузки: лучше запоминаются предложения, сказанные с соответствующей их содержанию интонацией, чем сказанные без интонации.

2. Увеличение убедительность вербального сообщения и побуждение реципиента к действию.

Убедительность вербального сообщения увеличивают:

- быстрый темп речи;

- громкий голос;

- меньшее расстояние до адресата;

- более интенсивный контакт глазами;

- прикосновение к адресату.

3. Эмоциональное заражение.

«Смех за кадром» делает комедию более смешной для зрителей.

4. Усиление когнитивной активности коммуникатора.

Когнитивную активность людей усиливает демонстрация позы, связанной с плохим настроением: люди, напряженно давившие на стол во время решения задач, более тщательно анализировали поступающую информацию, чем те, кто сидел расслабленно.

Несоответствие невербального поведения вербальному разрушает когнитивные процессы. В частности, люди хуже вспоминают позитивные прилагательные, которые они запоминали, стоя в позе подчиненности - на коленях, чем те, которые они запоминали стоя прямо.

5. Саморегуляция коммуникатором своего эмоционального состояния.

Копирование телесных выражений позитивных (счастье) и негативных (злость, скука, страх) эмоций (позы и мимики) приводит к их возникновению у коммуникатора.

Подавление невербального выражения эмоции приводит к меньшей интенсивности самой эмоции. Это касается как позитивных (радость), так и негативных (страх) эмоций.

Подавление эмоции может осуществляться с помощью действий - замещений (перекладывания конспектов, курения и т.д.).

6 Самораскрытие, выражение своих эмоций.

Невербальное поведение определяет: 
- характер эмоции коммуникатора. Например, для злобы характерны поднятые вверх плечи, вытянутые вперед руки, открывающие и закрывающие жесты, много жестов-иллюстраторов, высокая двигательная активность; для грусти - расслабленное тело, медленные движения; для отчаяния - плечи вперед, открывающие / закрывающие движения руками, экспансивные движения и т.д.;

- интенсивность эмоции коммуникатора.

7. Самопрезентация, результатом которой является формирование впечатления об индивидуальности коммуникатора: биологических особенностях; темпераменте; личностных чертах; коммуникативной компетентности; образе Я; эмоциональном состоянии.

Например, по данным американских исследований коммуникатор оценивается как:

- более дружелюбный и естественный, когда он улыбается, кивает головой, поддерживает контакт глазами;

- более активный / или суетливый, когда быстро говорит;

- более целеустремленный, волевой, когда говорит глухим, низким голоCOM;

- более компетентный, заслуживающий приема на работу, когда неотрывно смотрит на собеседника, активно жестикулирует, улыбается, говорит без запинок и с той же скоростью, что и слушатель, пахнет мужскими духами;

- более сильный, агрессивный, доминантный, наделенный лидерскими качествами, когда долго смотрит на собеседника и громко говорит;

- более искренний и достойный доверия, когда поддерживает контакт глазами, редко притрагивается к себе, активно жестикулирует;

- более интеллигентный, образованный, когда имеет приятный тембр и интонации;

- более симпатичный, когда поддерживает интенсивный контакт глазами, обладает большими зрачками и имеет привлекательную внешность;

- более согласный со своим партнером, когда вербальное согласие сопровождается поворотом головы к нему и контактом глазами.

8. Выражение отношения к партнеру, определение его статуса.

Невербальная коммуникация включает сведения о:

- желаемом уровне общения (социальная и эмоциональная близость или отдаленность);

- характере или типе отношений (доминирование - зависимость, расположение - нерасположение);

- динамике взаимоотношений (стремление поддерживать общение, прекратить его или «выяснять отношения» и т.д.).

Наглядно в невербальной коммуникации проявляются враждебность, доминантность, стремление выделиться.

Например, показателями доминантности являются:

- высокостатусные люди чаще смотрят на собеседника, когда говорят сами, но реже - когда слушают его;

- меньше улыбаются; 
- медленнее говорят;

- больше жестикулируют;

- чаще нависают над партнером, похлопывают собеседника по плечу;

- чаще меняют позы;

- поза более расслабленная;

- большее личностное пространство;

- их реципиенты устанавливают с ними большую дистанцию.

Показателями негативного отношения к реципиенту (например, инвалиду), отказа общаться с ним, являются:

- увеличение дистанции между собой и реципиентом;

- определенная поза (скрещенные на груди руки; сплетенные в замок пальцы, фиксирующие колено сидящего «нога на ногу»; отклонение спины назад);

- мышечное расслабление. Оно позволяет коммуникатору уменьшить количество собственных коммуникативных реакций, что создает ощущение безопасности.

Показателем взаимопонимания между партнерами является «синхронность» поз, их зеркальное отображение.

Лингвисты выделяют следующие функции невербальных компонентов: социальную (контактноустанавливающую); эмотивную, связанную с эмоциями адресанта; волютативную; аппелятивную (воздействие на адресата); фатическую (установление и поддержание коммуникативного контекста); дейктическую (указание на местоположение человека или объекта); жестовое изображение физических действий человека; риторическую (художественные невербальные средства).

Невербальные компоненты коммуникации могут выполнять функции их синтаксических составляющих (членов предложения): в роли подлежащего; обстоятельства; сказуемого; в роли прямого дополнения; в роли косвенного дополнения.

Выделяют следующие коммуникативные функции невербальных средств в процессе общения:

1) функция подсобного элемента, сопровождающего речевое высказывание;

2) функция замены отдельных элементов речевого высказывания.

Сказанное выше делает справедливым вывод о том, что обширный корпус невербальных компонентов реализуется в рамках коммуникативного хода участников общения, выполняя при этом гиперфункцию продолжения и развития дискурса в целом.

\section{Список литературы:}

1. Вайман С.Т. Парасловесный диалог // Филологические науки. 1980. № 2. С. 31-38.

2. Жалагина Т.А. Роль вербальных и невербальных компонентов в формировании фокуса внимания // Личностные аспекты языкового общения. Калинин: КГУ, 1989. С. 87-92.

3. Капанадзе Л.А., Красильникова Е.В. Жест в разговорной речи // Русская разговорная речь. М., Наука, 1973. С. 464-481.

4. Мейнерте С.Л. Паралингвистические и коммуникативные особенности сценической речи: Дис. ... канд. наук. М., 1984. 153 с. 
5. Морозова О.Н., Кажанова З.Н. Лингвистические и экстралингвистические аспекты перевода // Филологические науки. Вопросы теории и практики. Тамбов: Грамота, 2015, № 3 (45). Ч. III.

C. $129-132$.

6. Потапова Р.К. Коннотативная паралингвистика. М.: Триада, 1997. 63 с.

7. Серякова И.И. Лексико-семантические и коммуникативно-функциональные особенности языковых единиц, описывающих невербальные средства коммуникации «голос» в современном английском языке: Дис. ... канд. филол. наук. Киев, 1987. 182 с.

8. Стернин И.А. Коммуникативное поведение в структуре национальной культуры //

Этнокультурная специфика языкового сознания. М.: Наука, 1996. С. 13-20.

(C) 2015, Ильина И.Е.

Основные подходы к изучению невербальных средств коммуникации
(C) 2015, Ilina I.E.

Main approaches to the studying of nonverbal means of communication 